\title{
Adiposity, education and weight loss effort are independently associated with energy reporting quality in the Ontario Food Survey
}

\author{
Heather Ward ${ }^{1}$, Valerie Tarasuk ${ }^{1, *}$ and Rena Mendelson ${ }^{2}$ \\ 'Department of Nutritional Sciences, University of Toronto. 150 College St, Toronto Ontario, M5S 3E2, Canada: \\ ${ }^{2}$ School of Nutrition, Ryerson University, 350 Victoria Street, Toronto, Ontario, M5B 2K3, Canada
}

Submitted 6 March 2006: Accepted 25 September 2006: First published online 5 March 2007

\begin{abstract}
Objectives: To examine the associations of adiposity, dietary restraint and other personal characteristics with energy reporting quality.

Design/subjects: Secondary analysis of 230 women and 158 men from the 1997/98 Ontario Food Survey.

Methods: Energy reporting quality was estimated by ratios of energy intake (EI) to both basal metabolic rate (BMR) and total energy expenditure (TEE). Multivariate regression analyses were conducted to examine energy reporting quality between two dietary recalls and in relation to body mass index (BMI) with adjustment for potential confounders. Energy reporting quality was explored across categories of age, BMI, income, education, dieting status and food insecurity through analysis of variance (ANOVA).

Results: From the ANOVA, energy reporting quality was associated with BMI group, age category and weight loss for men and women, as well as with education among women $(P<0.05)$. The multivariate regression analyses indicated that energy reporting quality was positively associated with education and inversely associated with obesity and dieting. No associations were observed in relation to food insecurity or income $(P>0.05)$. EI:BMR and EI:TEE on the first and second 24-hour recalls were positively related $(P<0.0001$ for men and women). A higher proportion of variance in energy reporting quality was explained for women than for men $\left(R^{2}=0.19\right.$ and 0.14 , respectively).

Conclusions: Studies of diet and adiposity are probably hindered to some extent by BMI-related variation in energy reporting quality. Methods to address this issue are urgently needed if population surveys will continue to serve as the primary source of dietary intake data.
\end{abstract}

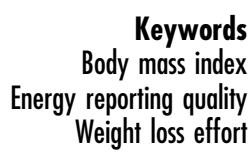

Keywords

reporting quality

Weight loss effort
Population health interventions to address the high prevalence of overweight and obesity require information about the association between dietary habits and weight status. However, error in self-reported dietary intake data has been observed in many populations ${ }^{1-10}$, and greater under-reporting has been noted among women ${ }^{1,2,6}$, those with higher weight or body mass index (BMI) ${ }^{1-10}$ and those who have reported some indication of weight loss effort $^{2,5,7}$. As such, studies of diet and adiposity are complicated by not only the increased risk of underreporting among those with greater adiposity, but also the potential for unusual dietary habits at the time of the survey such as deliberate weight loss effort or restricted intake due to food insecurity. The increased prevalence of under-reporting among overweight or obese individuals may simply be a marker of reduced energy intake (EI) among those trying to lose weight, but this is unclear from the existing research ${ }^{3,5,6}$. A clearer identification of factors that are associated with the quality of dietary reporting may be obtained by clarifying the independent contributions of weight loss effort and adiposity.

Under-reporters can be identified with a high level of accuracy using biomarkers such as doubly labelled water (DLW) or urinary nitrogen excretion ${ }^{11,12}$. However, because these methods are costly and place a burden on the participants, they are impractical for the validation of EI in large population studies. Energy under-reporters have therefore typically been identified through comparisons of reported EI with basal metabolic rate (BMR), a value estimated from height, weight and age category ${ }^{13}$. In previous research, participants were often identified as under-reporters or non-under-reporters based on their EI:BMR values in relation to specific cut-offs established by Goldberg ${ }^{2,4,5,10,14}$. With information about a population's 
physical activity level, the Goldberg cut-off can be used to evaluate the mean population bias in reported EI. However, this approach has limited sensitivity for identifying under-reporters at the individual level, and the application of a single cut-off point can result in genderand age-specific biases ${ }^{12,15}$. In addition, energy reporting quality is consistent over several data collection periods ${ }^{6,16}$, indicating that the error introduced by under-reporting cannot be diminished with increased days of intake data.

The 2005 Dietary Reference Intakes (DRIs) for energy include equations for estimating energy expenditure based on DLW studies of people with a wide range of age, weight and physical activity levels ${ }^{17}$. In contrast to the $\mathrm{BMR}$, these equations provide an estimate of total energy expenditure based on height, weight and age, as well as a measure of physical activity. Furthermore, the DRI equations are specific to BMI groups ${ }^{17}$. These equations were not developed specifically for evaluating dietary reports in population surveys; however, a comparison of reported EI with estimated energy expenditure can serve as an indicator of dietary reporting quality.

The primary goal of the present analysis was to examine adiposity, weight loss effort and other personal characteristics in relation to energy reporting quality, measured by the ratios of reported EI to the conventional BMR and the new DRI estimates of total energy expenditure ${ }^{17}$. Lower ratios are more likely than higher ratios to be indicative of energy under-reporting. A secondary objective of the present analysis was to examine the consistency of energy reporting quality across two dietary recalls within individuals. The Ontario Food Survey (OFS) provided the opportunity to conduct such analyses, as there was a high proportion of overweight and obese participants, and data on several measures related to adiposity and energy reporting quality were available.

\section{Methods}

\section{Sampling and recruitment}

The OFS was conducted between June 1997 and September 1998. A full description of the survey method has been published previously ${ }^{18}$. Participants were drawn from the Ontario Health Insurance Program (OHIP) database using a stratified multistage probability design, and were contacted by letter and follow-up phone call. The participants were randomly assigned to different days of the week to allow for systematic day of the week variations in dietary intake, and were interviewed in their homes. Data were collected from 707 women and 480 men. The second dietary recall was collected at least 8 days later from a subset of the sample, and was conducted on a different day of the week. The present analysis includes only the 230 women and 158 men who completed two dietary recalls. The study protocol was approved by the Ethics Research Board at the University of Toronto.

\section{Antbropometrics}

Participants were weighed to the nearest $0.5 \mathrm{~kg}$ on a calibrated mechanical dial scale, and height was measured with a measuring tape to the nearest $0.1 \mathrm{~cm}$. Height and weight measurements were obtained from $73 \%$ of men and $78 \%$ of women in the present analyses, with 27 and $22 \%$ of men and women, respectively, self-reporting one or both of height and weight values. BMI was defined as weight $(\mathrm{kg}) /[\text { height }(\mathrm{m})]^{2}$.

\section{Demographic and lifestyle characteristics}

An interviewer-administered questionnaire was used to collect data on participant's age, education and household income. Behaviours related to weight, the nature of occupational physical activity and the frequency and duration of vigorous leisure-time physical activity (LTPA) were addressed in a lifestyle questionnaire. Participants were asked if they were trying to lose, gain or maintain their current weight. Those who indicated that they were trying to lose weight were asked to identify from a list the methods they were using to achieve their weight loss. Participants were also asked four questions about their household food security over the past 12 months ${ }^{19}$. Individuals who gave an affirmative response to at least one question were considered to be in food-insecure households.

\section{Energy intake measurement}

Dietary intake data were collected in person with a standardised multiple-pass 24-hour recall. Portion size models, bowls, thickness indicators and measuring tapes were used to improve reporting accuracy. The interviewer recorded a list of all foods and beverages reported, probed this list for descriptive details and for other forgotten items, and reviewed the details of the 24-hour recall data with the participant. Data from the 24-hour recalls were coded and analysed by the Nutrition Research Division in the Food Directorate in Health Canada using the in-house Nutrition Survey System (NSS) software.

\section{Measurement of energy reporting quality}

The quality of self-reported EIs was first evaluated through a comparison of reported average EI with estimates of BMR (EI:BMR) ${ }^{13}$ and then with the estimated energy requirements (EERs) ${ }^{17}$. Data on the frequency and duration of physical activity throughout the day were required for the EER equations. Because limited data were available on occupational physical activity, the classification of participants' activity levels was based on LTPA. Up to four levels of activity can be identified with the EER equations; however, with the OFS data only two levels of physical activity could be distinguished. Participants who reported $30 \mathrm{~min}$ or more of LTPA daily were classified as 'low active', otherwise they were considered sedentary. Consistent with the DRI report, the equations for overweight and obese individuals are referred to as 
measures of total energy expenditure (TEE) for weight maintenance instead of EERs ${ }^{17}$. For consistency across the sample, the term TEE is applied to all participants throughout the present analyses. As suggested in the introduction, the application of cut-off points to identify under-reporters and non-under-reporters has limitations; therefore, in the present analyses, energy reporting quality has been examined as a continuous measure.

\section{Statistical analyses}

Statistical analyses were performed with SAS (version 9.1, 2003; SAS Institute Inc.). Interrelationships among the variables under study were tested using $\chi^{2}$ analyses. Energy reporting quality from the first 24-hour recall was regressed onto energy reporting quality from the second 24-hour recall in order to examine the within-person variation in energy reporting quality.

Analysis of variance (ANOVA) was used to test differences in energy reporting quality across categories of age, income, education, weight loss status and food insecurity. In order to meet the ANOVA requirement of a normally distributed dependent variable, EI:BMR and EI:TEE values were transformed using the Box-Cox method, in which maximum likelihood estimates are used to determine the optimal power transformation. For variables with more than two levels, comparisons of least square means with a Bonferroni correction for multiple comparisons were conducted to identify which groups were significantly different from each other.

Multivariate linear regression analyses were conducted in order to identify variables that were independently associated with energy reporting quality. The calculation of BMI from self-reported height and weight values tends to produce erroneously low BMI values ${ }^{20-24}$; therefore, a dichotomous variable for measured versus self-reported was also included in the adjusted models. The linear regression analyses were repeated excluding participants who had indicated they were attempting to lose weight at the time of the survey to examine how the expressed intention to lose weight may have affected observed associations with the ratios of reported EI:BMR and EI:TEE.

$R^{2}$ statistics are presented as an indicator of the amount of total variance in energy reporting quality that has been accounted for by variables in the models.

\section{Results}

\section{Interrelationships among variables}

Sample characteristics are presented in Table 1. Twentysix percent of men in the sample were obese and $29 \%$ were healthy weight, whereas among women, 31\% were obese and $40 \%$ were of healthy weight. Thirty-seven percent of men and $46 \%$ of women indicated that they were attempting to lose weight. Six per cent of men and
$18 \%$ of women responded affirmatively to at least one question regarding food insecurity.

$\chi^{2}$ analyses revealed that for men and women the proportion of participants reporting weight loss effort was greater among those identified as overweight or obese than those of healthy weight $(P<0.0001$ for men and women, data not shown). Education level and BMI classification were associated among women $(P<0.05)$ : $13 \%$ of healthy weight women had less than a high school education compared with $28 \%$ of obese women, and $21 \%$ of healthy weight women had completed university compared with $10 \%$ of obese women. Education level and BMI were not associated among men $(P>0.05)$. The proportion of women reporting weight loss effort differed across education levels $(P<0.05)$; however, weight loss effort did not increase or decrease in a linear fashion with education level. BMI group was not associated with food insecurity or income for men or women $(P>0.05)$.

\section{Energy reporting quality}

Linear regression analyses indicated that energy reporting quality on the first 24-hour recall was a significant predictor of energy reporting quality on the second 24hour recall, measured by either EI:BMR or EI:TEE $(P<0.0001$ for men and women). However, it accounted for only a limited amount of variance in energy reporting quality on the second day (EI:BMR, $R^{2} 0.14$ for men, 0.25 for women; EI:TEE, $R^{2} 0.12$ for men, 0.23 for women).

Table 1 Distribution of personal characteristics among the Ontario Food Survey participants

\begin{tabular}{|c|c|c|}
\hline & Men, $n(\%)$ & Women, $n(\%)$ \\
\hline \multicolumn{3}{|l|}{ Age (years) } \\
\hline $18-34$ & $25(16)$ & $62(27)$ \\
\hline $35-49$ & $41(26)$ & $65(28)$ \\
\hline $50-64$ & $49(31)$ & $59(26)$ \\
\hline $65-75$ & $43(27)$ & 44 (19) \\
\hline \multicolumn{3}{|l|}{ Income } \\
\hline Very low income & $16(11)$ & $38(21)$ \\
\hline Low income & $25(18)$ & $61(34)$ \\
\hline Middle income & $39(28)$ & 34 (19) \\
\hline High income & $60(43)$ & $46(26)$ \\
\hline \multicolumn{3}{|l|}{ Education } \\
\hline Less than high school & $33(21)$ & $52(23)$ \\
\hline High school & $33(21)$ & $58(25)$ \\
\hline Some post-secondary & $57(36)$ & $88(38)$ \\
\hline Graduated university & $35(22)$ & $31(14)$ \\
\hline \multicolumn{3}{|l|}{ Weight loss effort } \\
\hline No & $98(62)$ & $120(52)$ \\
\hline Yes & $60(38)$ & $110(48)$ \\
\hline \multicolumn{3}{|l|}{ Food insecurity } \\
\hline No & $149(94)$ & $188(82)$ \\
\hline Yes & $9(6)$ & $42(18)$ \\
\hline \multicolumn{3}{|l|}{ BMI groups* } \\
\hline Healthy weight & $41(26)$ & $93(40)$ \\
\hline Overweight & $71(45)$ & $66(29)$ \\
\hline Obese & $46(29)$ & $71(31)$ \\
\hline
\end{tabular}


EI:BMR was associated with age category for men and women (Table 2). EI:BMR was lower among men who reported weight loss effort compared with those who did not, and mean EI:BMR values decreased as BMI category increased from healthy weight to obese (Table 2). Among women, EI:BMR values increased with education level, were lower among women reporting weight loss effort and decreased as BMI categories increased (Table 2).

When the quality of energy reporting was measured by EI:TEE as opposed to EI:BMR, the only difference that emerged was that EI:TEE was significantly lower among women who reported food insecurity than those who did not (Table 2). Neither EI:BMR nor EI:TEE was associated with income for men or women (data not shown).

From the linear regression analyses of men, EI:BMR and EI:TEE were inversely associated with obesity and dieting, and positively associated with education (Table 3). Among women, EI:BMR was inversely associated with overweight, obesity and age; a positive association was detected for education (Table 3). Similarly, EI:TEE was positively associated with education and inversely associated with obesity and dieting; the inverse association between overweight and EI:TEE approached significance (Table 3). Neither food insecurity nor the nature of height and weight measurement (measured or self-reported) was associated with EI:BMR or EI:TEE among men or women
(Table 3). The $R^{2}$ statistic indicated that a greater proportion of variance in energy reporting quality was explained by the multivariate EI:BMR model relative to the EI:TEE model for men and women, with 14 and 19\% of the EI:BMR variance explained by all of the variables in the model (Table 3).

Upon exclusion of adults who reported weight loss efforts, EI:BMR and EI:TEE remained positively associated with education for women and negatively associated with obesity for men (Table 4). However, EI:BMR and EI:TEE were no longer associated with education for men, or with obesity for women; marginal associations with overweight were observed for EI:BMR among women (Table 4). Again, the $R^{2}$ values were greater for the EI:BMR models than for EI:TEE (Table 4), but were lower than in the previous set of linear regressions.

\section{Discussion}

Despite the differences in the calculation of BMR and TEE, both approaches to measuring energy reporting quality yielded robust associations with education, weight loss effort and BMI classification in the present analyses. These findings are in accord with another study in which weight loss effort was significantly associated with underreporting independent of $\mathrm{BMI}^{5}$, and with other studies in

Table 2 Personal characteristics associated with energy reporting quality among men and women*

\begin{tabular}{|c|c|c|c|c|c|c|}
\hline & \multicolumn{3}{|c|}{ Men } & \multicolumn{3}{|c|}{ Women } \\
\hline & $n$ & $\begin{array}{c}\text { EI:BMR }(n=158) \\
\text { Mean } \pm \text { SD }\end{array}$ & $\begin{array}{c}\text { El:TEE }(n=156) \dagger \\
\text { Mean } \pm \text { SD }\end{array}$ & $n$ & $\begin{array}{c}\text { El:BMR }(n=230) \\
\text { Mean } \pm \text { SD }\end{array}$ & $\begin{array}{c}\text { El:TEE }(n=230) \\
\text { Mean } \pm \text { SD }\end{array}$ \\
\hline \multicolumn{7}{|l|}{ Age (years) } \\
\hline $18-34$ & 25 & $1.31 \pm 0.30$ & $0.92 \pm 0.20$ & 62 & $1.38 \pm 0.46^{a, b}$ & $0.99 \pm 0.32^{a}$ \\
\hline $35-49$ & 41 & $1.42 \pm 0.35^{a}$ & $1.02 \pm 0.25^{a, b}$ & 65 & $1.13 \pm 0.40^{\mathrm{a}}$ & $0.83 \pm 0.29^{a}$ \\
\hline $50-64$ & 49 & $1.16 \pm 0.33^{a}$ & $0.86 \pm 0.24^{a}$ & 59 & $1.15 \pm 0.35^{\mathrm{b}}$ & $0.87 \pm 0.26$ \\
\hline $65-75$ & 43 & $1.23 \pm 0.32$ & $0.88 \pm 0.23^{b}$ & 44 & $1.18 \pm 0.34$ & $0.88 \pm 0.24$ \\
\hline$P$-value & & 0.002 & 0.009 & & 0.001 & 0.014 \\
\hline \multicolumn{7}{|l|}{ Education } \\
\hline Less than high school & 33 & $1.18 \pm 0.31$ & $0.85 \pm 0.22$ & 52 & $1.02 \pm 0.31^{a, b}$ & $0.76 \pm 0.23^{a, b}$ \\
\hline High school & 33 & $1.30 \pm 0.36$ & $0.93 \pm 0.25$ & 58 & $1.16 \pm 0.36$ & $0.84 \pm 0.26$ \\
\hline Some post-secondary & 57 & $1.29 \pm 0.35$ & $0.92 \pm 0.25$ & 88 & $1.32 \pm 0.44^{b}$ & $0.97 \pm 0.30^{\mathrm{b}}$ \\
\hline University & 35 & $1.31 \pm 0.33$ & $0.95 \pm 0.23$ & 31 & $1.33 \pm 0.39^{a}$ & $0.98 \pm 0.28^{a}$ \\
\hline$P$-value & & NS & NS & & $<0.0001$ & $<0.0001$ \\
\hline \multicolumn{7}{|l|}{ Weight loss effortł } \\
\hline No & 98 & $1.34 \pm 0.34$ & $0.96 \pm 0.24$ & 120 & $1.31 \pm 0.42$ & $0.96 \pm 0.29$ \\
\hline Yes & 60 & $1.16 \pm 0.31$ & $0.84 \pm 0.22$ & 110 & $1.11 \pm 0.36$ & $0.82 \pm 0.26$ \\
\hline$P$-value & & 0.002 & 0.0007 & & 0.0001 & 0.0003 \\
\hline \multicolumn{7}{|l|}{ Food insecure } \\
\hline No & 149 & $1.27 \pm 0.34$ & $0.91 \pm 0.24$ & 188 & $1.23 \pm 0.39$ & $0.91 \pm 0.28$ \\
\hline Yes & 9 & $1.29 \pm 0.36$ & $0.94 \pm 0.25$ & 42 & $1.13 \pm 0.47$ & $0.81 \pm 0.33$ \\
\hline$P$-value & & NS & NS & & NS & 0.031 \\
\hline \multicolumn{7}{|l|}{ BMI } \\
\hline Healthy weight & 41 & $1.41 \pm 0.30^{a}$ & $1.00 \pm 0.20^{a}$ & 93 & $1.37 \pm 0.37^{a}$ & $0.99 \pm 0.27^{a}$ \\
\hline Overweight & 71 & $1.29 \pm 0.34^{b}$ & $0.93 \pm 0.24$ & 66 & $1.15 \pm 0.31$ & $0.86 \pm 0.23$ \\
\hline Obese & 46 & $1.11 \pm 0.32^{\mathrm{a}, \mathrm{b}}$ & $0.82 \pm 0.23^{a}$ & 71 & $1.07 \pm 0.45^{\mathrm{a}}$ & $0.79 \pm 0.33^{a}$ \\
\hline$P$-value & & $<0.0001$ & 0.0007 & & $<0.0001$ & $<0.0001$ \\
\hline Adjusted $P$-value $\S$ & & 0.002 & 0.011 & & 0.001 & 0.004 \\
\hline
\end{tabular}

EI - energy intake; BMR - basic metabolic rate; TEE - total energy expenditure; SD - standard deviation; BMI - body mass index; NS - not significant.

${ }^{*} P$-values are the significance probability associated with the $F$-value; means with the same superscript letter are different $(P<0.05)$

†TEE not calculated for two men due to missing data on leisure-time physical activity.

$\ddagger$ Participant indicated use of dietary change, pills, exercise, etc. for weight loss.

$\S$ Adjusted for age, education, expressed intention to lose weight, food insecurity and BMI measurement type (measured or self-reported). 
Table 3 Multivariate regression analyses of energy reporting quality by gender

\begin{tabular}{|c|c|c|c|c|c|c|c|c|}
\hline & \multicolumn{3}{|c|}{ El:BMR } & \multirow[b]{2}{*}{$\begin{array}{l}\text { Adjusted } \\
\text { model } R^{2}\end{array}$} & \multicolumn{3}{|c|}{ El:TEE } & \multirow[b]{2}{*}{$\begin{array}{l}\text { Adjusted } \\
\text { model } R^{2}\end{array}$} \\
\hline & $\begin{array}{l}\text { Parameter } \\
\text { estimate }\end{array}$ & SE & $P$-value & & $\begin{array}{l}\text { Parameter } \\
\text { estimate }\end{array}$ & SE & $P$-value & \\
\hline $\operatorname{Men}(n=158)$ & & & & 0.14 & & & & 0.13 \\
\hline Overweight & -0.092 & 0.064 & NS & & -0.045 & 0.046 & NS & \\
\hline Obese & -0.237 & 0.073 & 0.001 & & -0.134 & 0.051 & 0.010 & \\
\hline Age category & -0.035 & 0.025 & NS & & -0.018 & 0.018 & NS & \\
\hline Dieting & -0.129 & 0.056 & 0.024 & & -0.108 & 0.040 & 0.008 & \\
\hline Education & 0.058 & 0.025 & 0.021 & & 0.046 & 0.018 & 0.010 & \\
\hline Food insecure & -0.008 & 0.113 & NS & & 0.019 & 0.080 & NS & \\
\hline Measured data for $\mathrm{BMI}^{\star}$ & 0.082 & 0.058 & NS & & 0.058 & 0.041 & NS & \\
\hline Women $(n=230)$ & & & & 0.19 & & & & 0.16 \\
\hline Overweight & -0.131 & 0.061 & 0.033 & & -0.076 & 0.044 & NS & \\
\hline Obese & -0.205 & 0.062 & 0.001 & & -0.132 & 0.045 & 0.004 & \\
\hline Age category & -0.064 & 0.024 & 0.008 & & -0.030 & 0.018 & NS & \\
\hline Dieting & -0.124 & 0.053 & 0.019 & & -0.081 & 0.038 & 0.035 & \\
\hline Education & 0.078 & 0.026 & 0.003 & & 0.059 & 0.019 & 0.002 & \\
\hline Food insecure & -0.075 & 0.059 & NS & & -0.061 & 0.050 & NS & \\
\hline Measured data for $\mathrm{BMI}^{*}$ & 0.083 & 0.066 & NS & & -0.070 & 0.043 & NS & \\
\hline
\end{tabular}

EI - energy intake; BMR - basic metabolic rate; TEE - total energy expenditure; SE - standard error; BMI - body mass index; NS - not significant $(P>0.05)$.

${ }^{*}$ Compared with self-reported data for BMI.

which adiposity was associated with under-reporting ${ }^{1-10}$. Among OFS participants, there was evidence of higher EI:BMR and EI:TEE among those with higher levels of education, independent of BMI classification and weight loss effort. In some studies, lower levels of education have been associated with greater under-reporting among women ${ }^{1,2,6}$ and men $^{2}$, but many authors have found no association between education and energy reporting quality among women ${ }^{3,25}$ or men ${ }^{1,3,6}$. The inconsistency of these findings may be due to variation in the dietary data collection methods and EI:BMR cut-off points for identifying under-reporters or to differences between the populations under study.

By conducting the linear regression analyses without the adults who were attempting to lose weight, we confirmed that some of the patterns of energy reporting quality observed in the full sample could not be accounted for by reported intention to lose weight. Other studies have chosen to remove participants who were dieting as their reported EI could be expected to be relatively $\operatorname{low}^{6,26}$. However, even after the removal of adults who were trying to lose weight, energy reporting quality remained inversely associated with obesity for men and positively associated with education for women despite a considerable decrease in sample size.

The high prevalence of weight loss effort within the OFS sample raises the question of whether reported intention to lose weight resulted in restricted EI or was merely a function of a desire for social approval. Two studies from the USA found that social approval scores were positively

Table 4 Multivariate regression analyses of energy reporting quality by gender among adults not indicating weight loss effort

\begin{tabular}{|c|c|c|c|c|c|c|c|c|}
\hline & \multicolumn{3}{|c|}{ El:BMR } & \multirow[b]{2}{*}{$\begin{array}{c}\text { Adjusted } \\
\text { model } R^{2}\end{array}$} & \multicolumn{3}{|c|}{ El:TEE } & \multirow[b]{2}{*}{$\begin{array}{c}\text { Adjusted } \\
\text { model } R^{2} \\
\end{array}$} \\
\hline & $\begin{array}{l}\text { Parameter } \\
\text { estimate }\end{array}$ & SE & $P$-value & & $\begin{array}{l}\text { Parameter } \\
\text { estimate }\end{array}$ & SE & $P$-value & \\
\hline Men $(n=98)$ & & & & 0.09 & & & & 0.06 \\
\hline Overweight & -0.116 & 0.075 & NS & & -0.054 & 0.053 & NS & \\
\hline Obese & -0.276 & 0.093 & 0.004 & & -0.161 & 0.066 & 0.017 & \\
\hline Age category & -0.030 & 0.031 & NS & & -0.011 & 0.023 & NS & \\
\hline Education & 0.040 & 0.032 & NS & & 0.031 & 0.022 & NS & \\
\hline Food insecure & 0.130 & 0.169 & NS & & 0.112 & 0.120 & NS & \\
\hline Measured data for BMI ${ }^{*}$ & 0.147 & 0.075 & 0.052 & & 0.107 & 0.054 & 0.050 & \\
\hline Women $(n=119)$ & & & & 0.15 & & & & 0.11 \\
\hline Overweight & -0.162 & 0.085 & 0.058 & & -0.097 & 0.061 & NS & \\
\hline Obese & -0.071 & 0.098 & NS & & -0.053 & 0.071 & NS & \\
\hline Age category & -0.085 & 0.033 & 0.013 & & -0.040 & 0.024 & NS & \\
\hline Education & 0.090 & 0.037 & 0.017 & & 0.062 & 0.027 & 0.025 & \\
\hline Food insecure & -0.136 & 0.108 & NS & & -0.116 & 0.078 & NS & \\
\hline Measured data for $\mathrm{BMI}^{*}$ & 0.056 & 0.085 & NS & & 0.049 & 0.061 & NS & \\
\hline
\end{tabular}

EI - energy intake; BMR - basic metabolic rate; TEE - total energy expenditure; SE - standard error; BMI - body mass index; NS - not significant $(P>0.05)$.

${ }^{\star}$ Compared with self-reported data for BMI. 
associated with dietary under-reporting for men and women ${ }^{27,28}$; the same trend was observed in another study of women, but only among those with college education or greater ${ }^{29}$. However, energy under-reporting and restricted EI are not necessarily mutually exclusive practices. Some evidence of concurrent energy restriction and under-reporting comes from a longitudinal study of Australian young women in which under-reporters lost weight over time but not as much as expected based on their reported EI. However, height and weight data were self-reported in this study, and there were no data on weight loss intention. In order to understand energy under-reporting and restricted dietary intake better, longitudinal studies that include measures of weight loss intention, dietary intake and weight status are required. Regardless of whether lower EI is genuine or a function of reporting error, dietary records that are not representative of usual dietary habit present a problem for researchers who are attempting to identify relationships between dietary patterns and health status.

The proportion of women reporting weight loss effort was similar among those with relatively low and high education levels, therefore this cannot account for the low EI:BMR values among women with the lowest education level. Another potential explanation is that the dietary data collection method was particularly effective for women with higher education. A prior study found that higher literacy scores were associated with higher reported EIs; the author suggested that the skills of reading and writing might be related to the use of language ${ }^{30}$. If higher literacy is associated with higher levels of education, the women with more education in the OFS may have had an advanced ability to communicate their intake. Furthermore, all of the OFS interviewers were highly educated women, having completed either university or a professional nursing programme. It is possible that the interviewers may have established a better rapport with those for whom they had the most in common (i.e. highly educated women) and thus obtained a more thorough dietary recall from these participants. Consideration of the demographics of the interviewers in relation to participants, as well as ensuring that dietary recalls are appropriate for participants across the spectrum of education levels, may improve the quality of dietary reports among those of lower education.

The present analyses were limited by the measure of physical activity in the OFS. The questions were not designed to measure total activity throughout the day, and the nature of the questions regarding occupational activity lacked the necessary detail to identify participants as having anything other than a relatively sedentary level of occupational activity. As such, overall physical activity may have been underestimated, resulting in relatively higher ratios of EI to BMR and TEE. Furthermore, only two levels of physical activity could be discerned from the available data; the crudeness of this approach may have contributed to the similarity between EI:BMR and EI:TEE values. Food insecurity was not associated with energy reporting quality in the OFS. This was counter to the expectation that individuals from households experiencing food insecurity might report a lower than expected EI. Also, food insecurity in some populations was associated with increased risk of obesity ${ }^{31-33}$, and obesity has been associated with energy reporting quality ${ }^{2-5,7-10}$. However, the use of a household-level measure of food insecurity over the past year may have impeded our ability to observe associations with individual-level energy reporting quality over 2 days. Furthermore, the food insecure categorisation in the present analyses included subjects who had reported relatively 'mild' household food insecurity. Therefore, it is possible that there were insufficient participants with food insecurity severe enough to be mistaken for poor energy reporting quality.

In addition to considering energy reporting quality in relation to a broad spectrum of factors separately for men and women, to our knowledge this is the first time that the DRI TEE equations have been applied for the study of under-reporting in a population survey. The method appears to yield results comparable with the traditional EI:BMR approach, though it is not known if this similarity would persist in the presence of more detailed data on physical activity.

It is preferable to improve data quality at the collection point rather than remove suspect reports or otherwise modify the data set. The present analyses suggest that the energy reports of highest quality come from adults with lower BMI, women with higher education or women who reported no current attempt to lose weight; however, the advancement of health research would be stunted if it were restricted to these groups alone. The substantial and ever-increasing body of evidence regarding the patterns of variation in energy reporting quality across population subgroups highlights the need for the development of methods to address this issue, and a reminder of the caution required when interpreting existing nutrition data.

\section{Acknowledgements}

Sources of funding: The Ontario Food Survey received funding from Health Canada, the Heart and Stroke Foundation (Ontario) and members of the Program in Food Safety, Nutrition and Regulatory Affairs at the University of Toronto.

Conflict of interest declaration: We have no other financial or contractual agreements that could cause or be perceived to cause a conflict of interest regarding this work.

Authorship responsibilities: H.W. carried out the statistical analyses and drafted the manuscript. V.T. made substantial contributions to the conception of the study, critically revised the manuscript and was a co-investigator of the Ontario Food Survey. R.M. was the Principal Investigator of 
the Ontario Food Survey, participated in the design of the study and provided critical feedback on the manuscript.

\section{References}

1 Bedard D, Statenstein B, Nadon S. Underreporting of energy intake from a self-administered food-frequency questionnaire completed by adults in Montreal. Public Health Nutrition 2004; 7: 675-81.

2 Briefel RR, Sempos CT, McDowell MA, Chien S, Alaimo K. Dietary methods research in the third National Health and Nutrition Examination Survey: underreporting of energy intake. American Journal of Clinical Nutrition 1997; 65(4 Suppl.): 1203S-9S

3 Johansson G, Wikman A, Ahren AM, Hallmans G, Johansson I. Underreporting of energy intake in repeated 24-hour recalls related to gender, age, weight status, day of interview, educational level, reported food intake, smoking habits and area of living. Public Health Nutrition 2001; 4: 919-27.

4 Johansson L, Solvoll K, Bjorneboe GE, Drevon CA. Underand overreporting of energy intake related to weight status and lifestyle in a nationwide sample. American Journal of Clinical Nutrition 1998; 68: 266-74.

5 Lafay L, Basdevant A, Charles M-A, Vray M, Balkau B, Borys $\mathrm{J}-\mathrm{M}$, et al. Determinants and nature of dietary underreporting in a free-living population: the Fleurbaix Laventie Ville Sante (FLVS) study. International Journal of Obesity 1997; 21: 567-73.

6 Price GM, Paul AA, Cole TJ, Wadsworth ME. Characteristics of the low-energy reporters in a longitudinal national dietary survey. British Journal of Nutrition 1997; 77: 833-51.

7 Pryer JA, Vrijheid M, Nichols R, Kiggins M, Elliot P. Who are the 'low energy reporters' in the Dietary and Nutritional Survey of British adults? International Journal of Epidemiology 1997; 26: 146-54.

8 Samaras K, Kelly PJ, Campbell LV. Dietary underreporting is prevalent in middle-aged British women and is not related to adiposity (percentage body fat). International Journal of Obesity and Related Metabolic Disorders 1999; 23: 881-8.

9 Stallone DD, Brunner EJ, Bingham SA, Marmot MG. Dietary assessment in Whitehall II: the influence of reporting bias on apparent socioeconomic variation in nutrient intakes. European Journal of Clinical Nutrition 1997; 51: 815-25.

10 Warwick PM, Reid J. Trends in energy and macronutrient intakes, body weight and physical activity in female university students (1988-2003), and the effects of excluding under-reporters. British Journal of Nutrition 2004; 92 : 679-88.

11 Bingham SA. Urine nitrogen as a biomarker for the validation of dietary protein intake. Journal of Nutrition 2003; 133(Suppl. 3): 921S-4S

12 Livingstone MB, Black AE. Markers of the validity of reported energy intake. Journal of Nutrition 2003; 133(Suppl. 3): 895S-920S

13 Schofield WN. Predicting basal metabolic rate, new standards and review of previous work. Human NutritionClinical Nutrition 1985; 39(Suppl. 1): 5-41.

14 Goldberg GR, Black AE, Jebb SA, Cole TJ, Murgatroyd PR, Coward WA, et al. Critical evaluation of energy intake data using fundamental principles of energy physiology: 1. Derivation of cut-off limits to identify under-recording. European Journal of Clinical Nutrition 1991; 45: 569-81.

15 Black AE. Critical evaluation of energy intake using the Goldberg cut-off for energy intake:basal metabolic rate. A practical guide to its calculation, use and limitations. International Journal of Obesity and Related Metabolic Disorders 2000; 24: 1119-30.

16 Black AE, Cole TJ. Biased over- or under-reporting is characteristic of individuals whether over time or by different assessment methods. Journal of the American Dietetic Association 2001; 101: 70-80.

17 Institute of Medicine. Dietary Reference Intakes for Energy, Carbohydrate, Fiber, Fat, Fatty Acids, Cholesterol, Protein, and Amino Acids. Washington, DC: National Academies Press, 2005.

18 Mendelson R, Tarasuk V, Chappell J, Brown H, Anderson G. Report of Ontario Food Survey [online], 2003. Available athttp://www.ryerson.ca/ foodnut/facultyandstaff/ontario_ Food_Survey_Report_June_2003.pdf

19 Carlson SJ, Andrews MS, Bickel GW. Measuring food insecurity and hunger in the United States: development of a national benchmark measure and prevalence estimates. Journal of Nutrition 1999; 129(2S Suppl.): 510S-6S.

20 Kuczmarski MF, Kuczmarski RJ, Najjar M. Effects of age on validity of self-reported height, weight, and body mass index: findings from the Third National Health and Nutrition Examination Survey, 1988-1994. Journal of the American Dietetic Association 2001; 101: 28-34.

21 Kuskowoska-Wolk A, Karlsson P, Stolt M, Rossner S. The predictive validity of body mass index based on selfreported height and weight. International Journal of Obesity 1989; 13: 441-53.

22 Kuskowoska-Wolk A, Bergstrom R, Bostrom G. Relationship between questionnaire data and medical records of height, weight, and body mass index. International Journal of Obesity 1992; 16: 1-9.

23 Nawaz H, Chan W, Abdulrahman M, Larson D, Katz DL. Selfreported weight and height: implications for obesity research. American Journal of Preventive Medicine 2001; 20: 294-8.

24 Rowland ML. Self-reported weight and height. American Journal of Clinical Nutrition 1990; 52: 1125-33.

25 Hall KD, Stephen AM, Reeder BA, Muhajarine N, Lasiuk G. Diet, obesity and education in three age groups of Saskatchewan women. Canadian Journal of Dietetic Practice and Research 2003; 64: 181-8.

26 Krebs-Smith SM, Graubard BI, Kahle LL, Subar AF, Cleveland LE, Ballard-Barbash R. Low energy reporters vs others: a comparison of reported food intakes. European Journal of Clinical Nutrition 2000; 54: 281-7.

27 Novotny JA, Rumpler WV, Riddick H, Hebert JR, Rhodes D, Judd JT, et al. Personality characteristics as predictors of underreporting of energy intake on 24-hour dietary recall interviews. Journal of the American Dietetic Association 2003; 103: 1146-51

28 Tooze JA, Subar AF, Thompson FE, Troiano R, Schatzkin A, Kipnis V. Psychosocial predictors of energy underreporting in a large doubly labeled water study. American Journal of Clinical Nutrition 2004; 79: 795-804.

29 Hebert JR, Peterson KE, Hurley TG, Stoddard AM, Cohen N, Field $\mathrm{AE}$, et al. The effect of social desirability trait on selfreported dietary measures among multi-ethnic female health center employees. Annals of Epidemiology 2001; 11: 417-27.

30 Johnson RK, Soultanakis RP, Matthews DE. Literacy and body fatness are associated with underreporting of energy intake in US low-income women using the multiple-pass 24-hour recall: a doubly labeled water study. Journal of the American Dietetic Association 1998; 98: 1136-40.

31 Olson CM. Nutrition and health outcomes associated with food insecurity and hunger. Journal of Nutrition 1999; 129(2S Suppl.): 521S-4S.

32 Sarlio-Lahteenkorva S, Lahelma E. Food insecurity is associated with past and present economic disadvantage and body mass index. Journal of Nutrition 2001; 131: 2880-4.

33 Townsend MS, Peerson J, Love B, Achterberg C, Murphy SP. Food insecurity is positively related to overweight in women. Journal of Nutrition 2001; 131: 1738-45. 